\title{
Editorial: Increasing the Ambition of Climate Change Mitigation in Agriculture Whilst Meeting the Sustainable Development Goals (SDGs) and Food Policy Aims
}

\author{
Claudia Heidecke $^{1 *}$, Eva Wollenberg ${ }^{2}$ and Robert Rees ${ }^{3}$ \\ ${ }^{1}$ Coordination Unit Climate, Thuenen-Institute, Braunschweig, Germany, ${ }^{2}$ Agriculture and Food Security Research Program \\ (CCAFS), University of Vermont and CGIAR Research Program on Climate Change, Agriculture and Food Security (CCAFS), \\ Burlington, VT, United States, ${ }^{3}$ Carbon Management Centre, Scotland's Rural College (SRUC), Edinburgh, United Kingdom
}

Keywords: climate change, agriculture, targets, ambition, GHG emissions, policy, mitigation

Editorial on the Research Topic

Increasing the Ambition of Climate Change Mitigation in Agriculture Whilst Meeting the Sustainable Development Goals (SDGs) and Food Policy Aims

Reducing agriculture's impact on the climate is necessary if international targets are to be met (IPCC, 2018; Leahy et al.). Numerous estimates exist for the reduction potential of greenhouse gas emissions in agriculture (Smith et al., 2008; Griscom et al., 2017, 2020; Frank et al., 2018; IPCC, 2018; Roe et al., 2019), yet little progress has been made in implementing measures at

OPEN ACCESS

Edited and reviewed by: Stephen Whitfield,

University of Leeds, United Kingdom

*Correspondence:

Claudia Heidecke

claudia.heidecke@thuenen.de

Specialty section:

This article was submitted to Climate-Smart Food Systems,

a section of the journal

Frontiers in Sustainable Food Systems

Received: 23 March 2021 Accepted: 08 April 2021 Published: 30 April 2021

Citation:

Heidecke $C$, Wollenberg $E$ and Rees $R$ (2021) Editorial: Increasing the Ambition of Climate Change Mitigation in Agriculture Whilst Meeting the Sustainable Development Goals (SDGs) and Food Policy Aims. Front. Sustain. Food Syst. 5:684731. doi: 10.3389/fsufs.2021.684731 the scales necessary to mitigate or adapt to climate change. The IPCC Special Reports (IPCC, 2018 , 2019) highlight the urgency and complexities of achieving sufficient mitigation and the particular challenges faced by agriculture and the land-use sector, where food security is paramount, environmental objectives are often seen as an additional burden by farmers, and emissions are likely to increase to meet growing global food demand. While mitigation targets should be ambitious, they also need to be realistic, taking into consideration these special features of the agriculture sector and what is possible to achieve in the short-term. Generating mitigation as a co-benefit of current agricultural development (Grewer et al., 2018) will not be enough.

In 2018 around 300 scientists and stakeholders from over 50 different countries met in Berlin for the "International Conference on Agricultural GHG Emissions and Food Security-Connecting Research to Policy and Practice" to discuss scientific options, practice and enhance policy actions to reduce greenhouse gas $(\mathrm{GHG})$ emissions from agriculture. One of the meeting's main conclusions was that more effort is needed to incentivize, finance and scale mitigation solutions. Policy and investment are needed to support large-scale implementation, including demonstration sites, knowledge brokerage, extension services and technical assistance to support practical and scalable solutions, and help farmers implement good practices to mitigate GHGs.

In this special topic section, five papers tackle questions related to achieving ambitious climate change mitigation in agriculture and highlight some of the key challenges and opportunities. Leahy et al. see the necessity of a comprehensive and accelerated effort to bridge the gap from modeled emissions to realistic policy pathways. Lynch et al. call for differentiating the role of shorter-lived methane and nitrous oxide emissions from longer-lived carbon dioxide on warming and prioritizing mitigation accordingly. They also advocate multi-objective mitigation and adaptation planning, that takes food security and other development goals into account. de Pinto et al. summarize 
studies that evaluate the global threats from land degradation and analyse how full integration of crop production with restoration could impact food production, forest carbon stocks, and GHG emissions. Arango et al. discuss the constraints to achieving GHG emission reduction targets in the livestock sector of Latin America and the need for comprehensive market, policy and technical interventions. Reay et al. highlight the need for attention to local contexts and integrated approaches to achieving net zero targets in Scotland and the role of research in informing rural policy and landowner actions. Strategies for large-scale impact are therefore needed that provide technical options, but also support processes for tailoring these to local conditions. This could include improving local government extension and research capacities, providing farmers with interactive knowledge platforms and help them identify appropriate mitigation and adaptation practices rather than silver-bullet solutions, or emphasizing outcome-based interventions.

Together the articles make the point that ambition in the agriculture sector needs to be more realistic about what is feasible. Real barriers exist that are difficult to overcome even in higher income countries. Nevertheless, ambition can be increased and priority options are identified.

With regards to more realistic targets, Leahy et al. remind us that targets set according to the 1.5 or 2 degree Paris Agreement goals and theoretical mitigation potentials are based on optimistically modeled scenarios where carbon prices are assumed to exist. Yet most countries have been opposed to carbon pricing for agriculture, with New Zealand being the only country enabling mandatory carbon pricing. Other interventions are generally less scalable or efficient, such as the offset schemes found in Australia, California, and Alberta, Canada; voluntary markets, and novel technical options. Arango et al. caution that the difficulties of achieving widespread adoption of new practices also make targets unrealistic.

Lynch et al. argue for more impact-related net zero targets that take into account the different warming impacts of carbon dioxide, methane and nitrous dioxide. Current targets aggregate the three gases, even though the effects of methane are higher in the short-term and lower in the long-term than carbon dioxide.

The articles show that mitigation implementation has been severely constrained by a number of barriers. Potential negative impacts on farmers' livelihoods, loss of competitive advantage, food security risks, or risk of leakage have discouraged countries' from use of strict regulatory measures (Leahy et al.). High

\section{REFERENCES}

Frank, S., Beach, R., Havlík, P., Valin, H., Herrero, M., Mosnier, A., et al. (2018). Structural change as a key component for agricultural non-CO2 mitigation efforts. Nat. Commun. 9:1060. doi: 10.1038/s41467-018-03489-1

Grewer, U. J., Nash, N., Gurwick, L., Bockel, G., Galford, M., Richards, C., et al. (2018). Analyzing the greenhouse gas impact potential of smallholder development actions across a global food security program. Environ. Res. Lett. 13:044003. doi: 10.1088/1748-9326/aab0b0

Griscom, B. W., Adams, J., Ellis, P. W., Houghton, R. A., Lomax, G., Miteva, D. A., et al. (2017). Nature climate solutions. Proc. Natl. Acad. Sci. U.S.A. 114, 11645-11650. doi: 10.1073/pnas.1710465114 initial costs, lack of credit, poor extension or technical advice, underdeveloped grass seed distribution systems, and weak markets for sustainable meat or milk have slowed the uptake of innovation of mitigation practices related to herd management, improved feed or feed additives for reducing emissions from livestock in Latin America (Arango et al.).

The articles' authors generally agreed that achieving more ambitious, but realistic implementation goals will require drawing on multiple interventions, requiring integrated approaches and attention to local contexts. de Pinto et al. for example, show the potential impacts of integrating crop production with forest land restoration, to promote better community support for the forest interventions. Their modeling demonstrated that significant, multiple benefits could be achieved for food prices, productivity and climate change mitigation. Reay et al. discuss the need for regional land use plans in Scotland as a way to manage locally appropriate trade-offs and interventions to achieve net zero emissions. They stress the need for integrated biophysical and social science assessments of land use strategies to better understand changes, for example in incomes, community cohesion, or employment and avoid what they call "carbon blinkers."

A comprehensive and realistic picture is therefore needed to formulate ways forward for a transition of the agriculture sector under the Paris Agreement. This will require evaluating and addressing technical frontiers, policy and market failures, and setting targets that can be reported again in short-time horizons, such as five years. We need to also develop strategies that support high impact at large scales but are tailored to local conditions.

As policy makers at global and national levels aim to achieve more ambitious progress in climate change mitigation, pragmatic attention is therefore needed to address future political, socio-economic and biophysical barriers to make even more mitigation feasible. Bolder steps toward larger-scale policy design will require comprehensive and integrated use of multiple solutions and taking into account local conditions to ensure relevant implementation.

\section{AUTHOR CONTRIBUTIONS}

$\mathrm{CH}$ wrote first draft. EW wrote second draft. RR edited the third draft. All authors contributed to the article and approved the submitted version. 
Security, and Greenhouse Gas Fluxes Interrestrial Ecosystems, eds P. R. Shukla, J. Skea, E. Calvo Buendia, V. Masson-Delmotte, H.-O. Pörtner, D. C. Roberts, P. Zhai, R. Slade, S. Connors, R. van Diemen, M. Ferrat, E. Haughey, S. Luz, S. Neogi, M. Pathak, J. Petzold, J. Portugal Pereira, P. Vyas, E. Huntley, K. Kissick, M. Belkacemi, and J. Malley. (in press).

Roe, S., Streck, C., Obersteiner, M., Frank, S., Griscom, B., Drouet, L., et al. (2019). Contribution of the land sector to a $1.5^{\circ} \mathrm{C}$ world. Nat. Clim. Change. 9, 817-828. doi: 10.1038/s41558-019-0591-9

Smith, P., Martino, D., Cai, Z., Gwary, D., Janzen, H., Kumar, P., et al. (2008). Greenhouse gas mitigation in agriculture. Phil. Trans. R. Soc. Lond. B: Biol. Sci. 363, 789-813. doi: $10.1098 /$ rstb.2007.2184
Conflict of Interest: The authors declare that the research was conducted in the absence of any commercial or financial relationships that could be construed as a potential conflict of interest.

Copyright $\odot 2021$ Heidecke, Wollenberg and Rees. This is an open-access article distributed under the terms of the Creative Commons Attribution License (CC BY). The use, distribution or reproduction in other forums is permitted, provided the original author(s) and the copyright owner(s) are credited and that the original publication in this journal is cited, in accordance with accepted academic practice. No use, distribution or reproduction is permitted which does not comply with these terms. 